\title{
Wide-angle memories of close-up scenes: A demonstration of boundary extension
}

\author{
CARMELA V. GOTTESMAN and HELENE INTRAUB \\ University of Delaware, Newark, Delaware
}

\begin{abstract}
Boundary extension refers to a tendency to remember seeing a greater expanse of a scene than was shown in a photograph. It is hypothesized that the view shown in the stimulus activates expectations about the scene's layout just outside the picture's borders. Following presentation, the viewer remembers having seen this expected information, and this yields boundary extension. We provide photographs and instructions for conducting two brief demonstrations of the phenomenon and provide materials for a related class experiment on the journal's World-Wide Web site. These demonstrations of boundary extension provide graphic illustrations of the role of schematic expectancies in the representation of scenes and help to illustrate the role of real-world knowledge in cognition.
\end{abstract}

Look at the photographs presented in Figure 1. If you were to study these photographs carefully and sketch them from memory a few minutes later, what kinds of errors do you think you might make? To what extent would you expect your errors to differ from those made by others? Interestingly, it has been shown that there is a rather large representational error that viewers tend to make when remembering scenes. Examples of the error will be presented shortly. If you would like to experience this phenomenon yourself before seeing some typical drawings, please take the time now to study the pictures for $10-15 \mathrm{sec}$ and then cover them completely before reading further.

On a sheet of paper draw a $4 \times 6$ in. rectangle for each of the pictures. Consider the rectangle's edges to be the edges of the picture you studied and sketch in the objects and details from memory. Do not continue reading until you have completed your drawings.

Figure 2 shows two representative drawings made by observers after viewing the pictures shown in Figure 1. To evaluate the distortion, look closely at the pictures' boundaries. Note that in Figure 2, panel A, the drawing shows a more wide-angle view of the scene than did the photograph (Figure 1, panel A). In the remembered view, the garbage cans are not cropped and they cover a smaller area within the picture space. For example, the upright lid in the foreground was drawn to cover only $45 \%$ of the area that it covered in the stimulus. The drawing shows more of the pavement, the sky, and the fence than were actually present. The effect is even more dramatic in the case of the fork (Figure 2, panel B). In this case, when the boundaries were extended, much more of the fork's handle and more of the bowl of spaghetti were drawn than had been

This paper was supported by National Institute of Mental Health Grant MH54688-01 A1 to H.I. Correspondence should be addressed to C. V. Gottesman, University of Oklahoma, Department of Psychology, 455 West Lindsey, Norman, OK 73019 (e-mail: cvgottesman@ou.edu) or to $\mathrm{H}$. Intraub, Department of Psychology. University of Delaware, Newark, DE 19716 (e-mail: intraub(audel.edu). present in the stimulus. In fact, boundary extension was so great that the head of the fork was drawn to cover only $12 \%$ of its original area.

What viewers seem to remember is a more wide-angle view of the scene than was shown in the photograph. They remember having seen information that was not present, but that was likely to have existed just beyond the camera's point of view. The phenomenon, referred to as boundary extension, was first reported by Intraub and Richardson (1989). They found that boundary extension appeared to be "the rule, rather than the exception" when viewers remembered photographs depicting relatively close-up views.

For example, in one experiment, boundary extension occurred in $95 \%$ of the 133 drawings made by 37 participants (Intraub \& Richardson, 1989, Experiment 1). As seen in the example described earlier, the magnitude of boundary extension can be very large. For example, Intraub and Berkowits (1996) showed viewers seven closeup views of scenes for $15 \mathrm{sec}$ each and immediately after presentation asked them to draw the pictures from memory. Viewers tended to draw the close-up pictures with such extended boundaries that, on average, objects were reduced to one third of their original size within the picture space.

Boundary extension is not an artifact of how people draw. The tendency to remember having seen a more wideangle view has been demonstrated in a variety of recognition memory tests (e.g., Intraub, Bender, \& Mangels, 1992; Intraub \& Richardson, 1989; Nyström, 1993). In a typical experiment, participants are shown a series of $16-20$ pictures. They are then shown pictures of the same scenes and are asked to indicate on a 5-point rating scale whether the view in the test picture is the same, more of a closeup, or more of a wide-angle view than that in the stimulus.

When the test picture is identical to the stimulus picture, viewers tend to rate it as looking "closer-up" than before, thus indicating that the remembered representation has extended boundaries. When presented with distractors that show a more "wide-angle" or a more "close-up" view than 

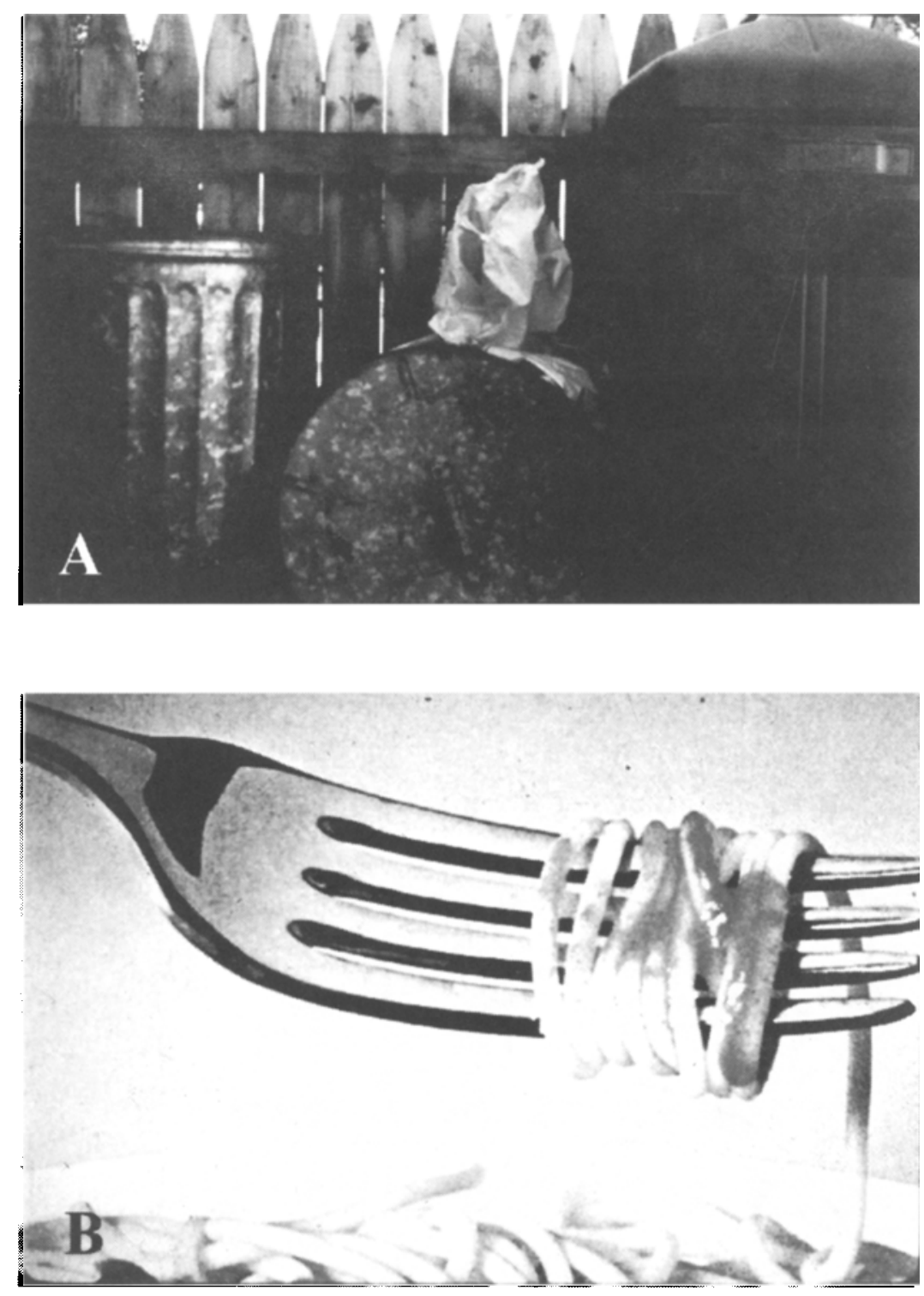

Figure 1. Two close-up views of common scenes. To perform a brief demonstration while reading the paper, refer to the text.

the original, observers are more likely to mistake the wideangle distractor as being the picture they saw before than as the close-up distractor. Even when a distractor is correctly recognized as such, wide-angle distractors are rated as looking more like the stimulus than are close-up distractors. This asymmetrical response pattern provides additional evidence for the presence of a unidirectional distortion.

Boundary extension is very robust and has been replicated in many experiments (e.g., Intraub et al., 1992; Intraub \& Berkowits, 1996; Legault \& Standing, 1992; Nyström, 1993). The phenomenon is so strong that even when participants were presented with a boundary extension demonstration and were then warned to guard against it, the effect was merely attenuated, not eliminated (Intraub \& Bodamer, 1993).

Why should this consistent, unidirectional error occur? In contrast to experiments in which misleading information is presented (e.g., Loftus \& Palmer, 1974; for review, see Ayers \& Reder, 1998), in boundary extension experiments there is no deception. In fact the participants in these studies are presented with small sets of very simple scenes and are instructed to pay close attention to the layout, including specific reference to the objects and the background.

Intraub and her colleagues (e.g., Intraub et al., 1992; Intraub, Gottesman, Willey, \& Zuk, 1996) have proposed that 

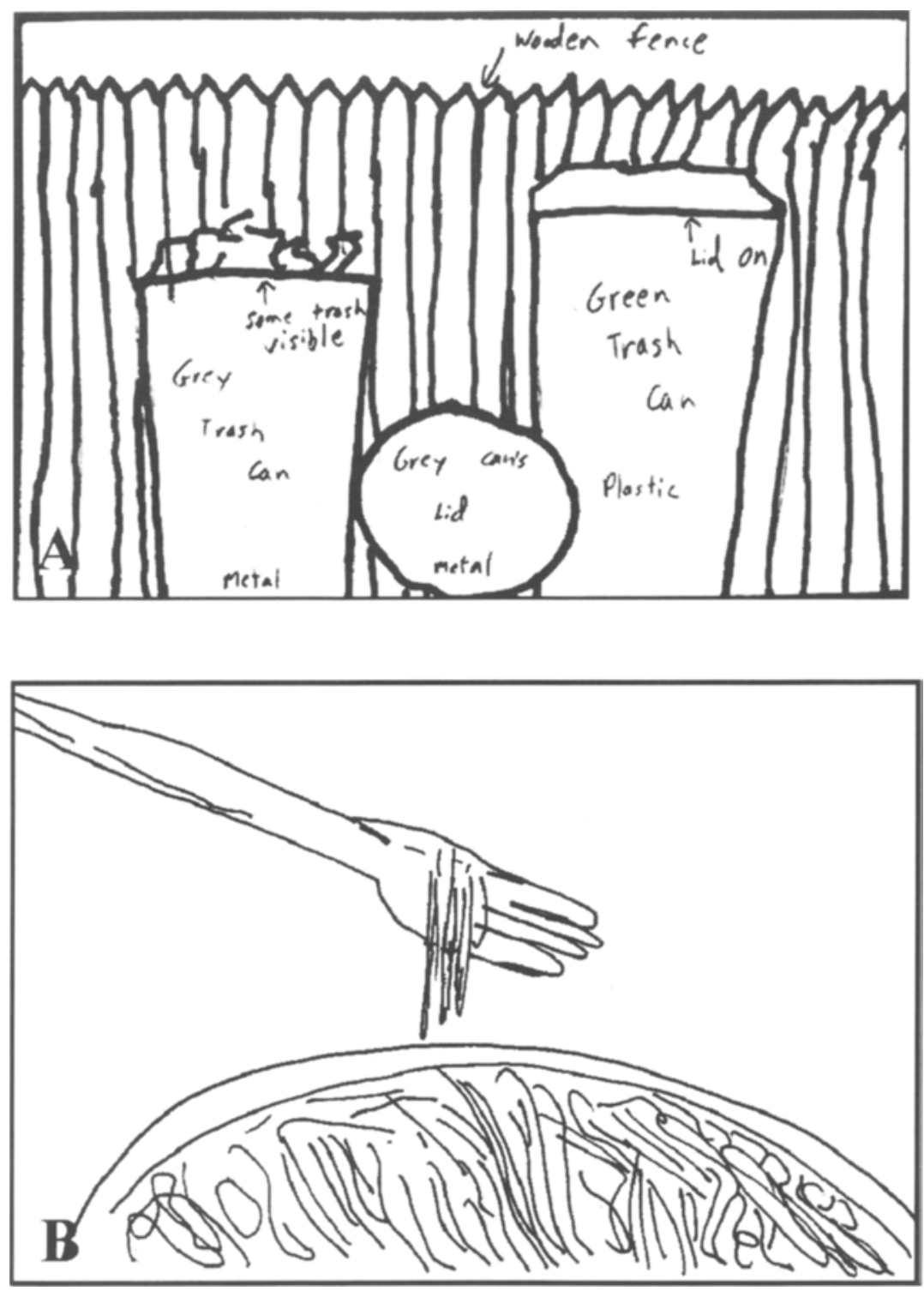

Figure 2. Drawings of the photographs in Figure 1. The retention interval was 48 hours for the drawing in panel $A$ and approximately 1 min for the drawing in panel $B$. Each drawing depicts a greater expanse of the scene than was actually shown in the photograph.

boundary extension is caused by the activation of a perceptual schema - a schematic representation of the scene's likely layout. This concept is similar to the mental schema proposed by Hochberg $(1978,1982)$. Intraub and her colleagues pointed out that at any given moment, the human observer is not able to view a scene in its entirety. With each fixation, a new region of the scene is brought into view. In addition to this, during each fixation, the best visual acuity is available for only that small area of the scene that falls on the fovea, with acuity dropping off rather sharply for information in the periphery. They suggested that the perceptual schema provides a framework within which newly fixated information can be understood.

According to this hypothesis, a picture is analogous to a single glimpse of the world, and the visual system treats it in much the same way. When we view a picture of a scene, the visual system rapidly and automatically extrapolates beyond the borders of that view. Boundary extension is thought to occur because the expected regions just outside a picture's borders are so integral to comprehension of the picture that the expected information becomes incorporated in the viewer's mental representation. 
For example, according to this hypothesis, to understand the garbage can scene (Figure 1, panel A), it is necessary to understand that the cropped garbage pails, the fence, the pavement, and the sky all continue beyond the view shown in the picture. This understanding is conveyed through activation of the perceptual schema. Later, when the pictures are retrieved from memory, viewers think they actually saw information that they actually only understood to exist, and this yields boundary extension in memory.

Consistent with this hypothesis, Intraub et al. (1996) demonstrated that boundary extension does not require a long retention interval to occur. In their experiment, they presented viewers with 42 triads of photographs. Each photograph in a triad was presented for $333 \mathrm{msec}$ with no interstimulus interval. Each triad was followed by a $1-\mathrm{sec}$ retention interval and a repetition of one of the three pictures. (A visual mask was presented during the retention interval.) Participants rated the repeated picture on the same 5-point scale described earlier to indicate whether the picture was the same as before or showed a more closeup or more wide-angle view. Boundary extension was obtained for pictures in all three serial positions, including the final picture, which had been repeated only $1 \mathrm{sec}$ after its initial presentation.

The perceptual schema hypothesis is also consistent with the pattern of results obtained when boundary memory is tested for picture views ranging from close-up to wide-angle. A number of experiments have shown that boundary extension is greatest for close-ups and decreases as more wide-angle views are presented. Little or no boundary extension is obtained for the most wide-angle views (e.g., Intraub et al., 1992; Intraub \& Berkowits, 1996). The perceptual schema hypothesis can readily explain these results given the following assumption: the most salient area of a simple scene is the area around the main object. In a close-up, much of this salient area falls outside the borders of the picture. The contents of the scene just outside the borders are highly predictable and are readily incorporated into the mental representation of the picture. However, as increasingly wide-angle views of the object are presented, more (and eventually all) of this salient area will be present in the picture itself.

Thus, according to the perceptual schema hypothesis, the degree of boundary extension depends on the particular view shown. However, for boundary extension to occur at all, it is necessary for the picture to depict a partial view of a continuous scene. Only a partial view should yield expectations about what is beyond the picture's boundaries.

Intraub, Gottesman, and Bills (1998) tested this hypothesis by contrasting boundary memory for drawings of objects in a scene context and drawings of the same objects on blank backgrounds (similar to dictionary drawings). A scene context yielded boundary extension, but a blank background did not. However, when participants viewed the same pictures of objects on blank backgrounds while imagining a scene context, boundary extension oc- curred. Apparently, a schematic representation of scene layout can be activated through either a bottom-up or top-down route with the same effect on memory.

\section{BOUNDARY EXTENSION DEMONSTRATION}

The demonstrations presented in this paper illustrate the boundary extension phenomenon and can be used to support discussions of the role of top-down knowledge in perception and cognition. Boundary extension is particularly suited for a classroom demonstration because it is robust, easy to do, and requires just a few minutes of class time. The results are readily apparent. Students can see the boundary extension effect in their own drawings without having to collect group data. However, the instructor can choose to include a quantitative analysis of the phenomenon in the context of the demonstration. (The method for quantifying the effect will be described in the next section.)

This paper describes two versions of the demonstration: (1) a brief one involving the two pictures shown in Figure 1 , and (2) a slightly longer one involving the four photographs shown in Figure 3. The former provides a basic demonstration of the phenomenon, and the latter can be used to contrast the perceptual schema hypothesis with some of the alternative explanations that will be discussed shortly. Both of these demonstrations are suitable for courses of any size, including large lecture courses in introductory psychology. For laboratory courses in which a more in-depth treatment of scene memory would be appropriate, we have included on the journal's World-Wide Web site the stimuli (digitized color photographs) and instructions necessary to replicate Intraub and Berkowits (1996, Experiment 1). (See editorial at the beginning of this issue for the address.) This experiment allows the student to test the effects of picture view (close-up, prototypic, and wide-angle views of the same seven scenes) on memory using a recognition procedure.

\section{Stimuli and Procedure for Both Demonstrations}

The black-and-white pictures in either figure can be copied onto separated overheads or handouts or can be digitized and presented on a computer monitor (digitized color versions of all the figures are available on the journal's World-Wide Web site).

The stimuli from the longer demonstration (Figure 3) were selected from the picture set used by Intraub and Berkowits (1996). The designation of "close-up" or "prototypic" view was determined on the basis of collected norms (see Intraub \& Berkowits, 1996). Note that the two close-ups that were selected contain cropped objects and the prototypic views do not.

Response sheets should simply contain an outline rectangle with the same aspect ratio $(1: 1.5)$ as the stimuli. To follow the procedure in previous studies, we suggest 


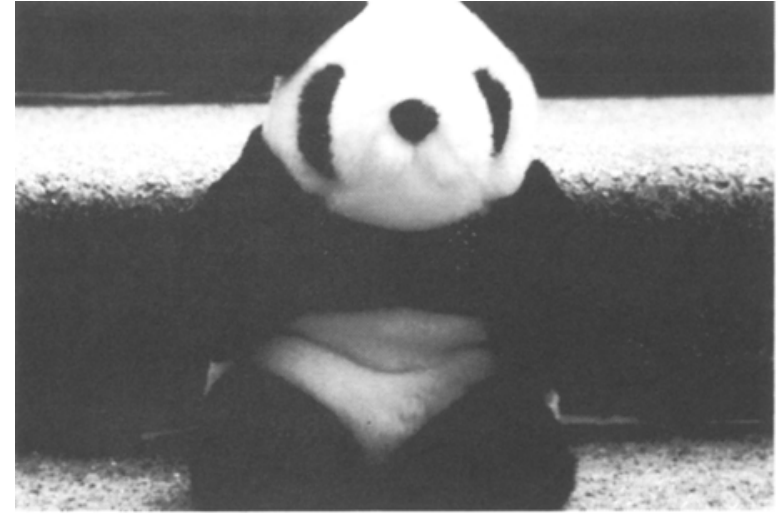

A

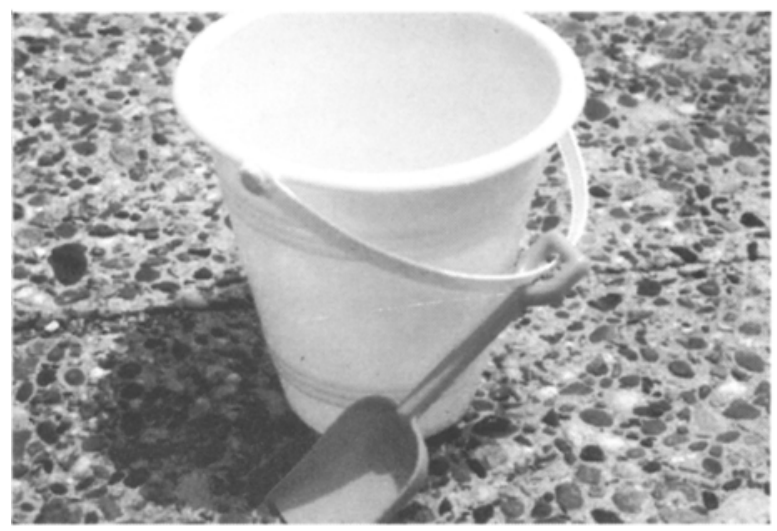

$\mathrm{C}$

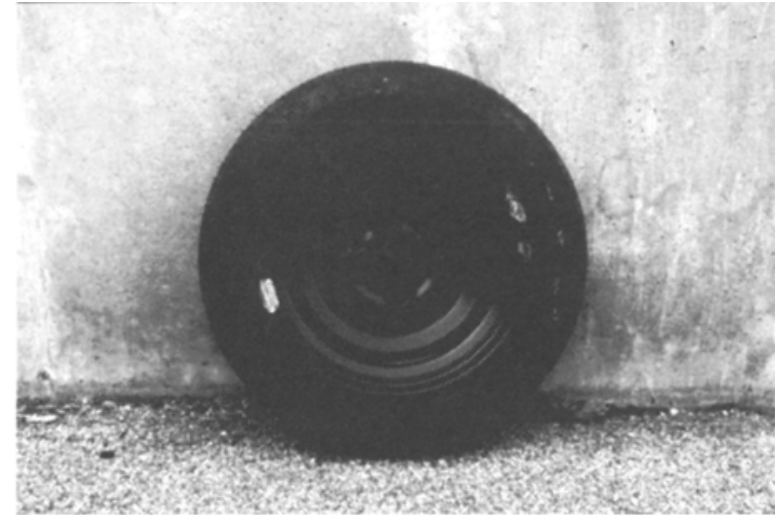

$\mathrm{B}$

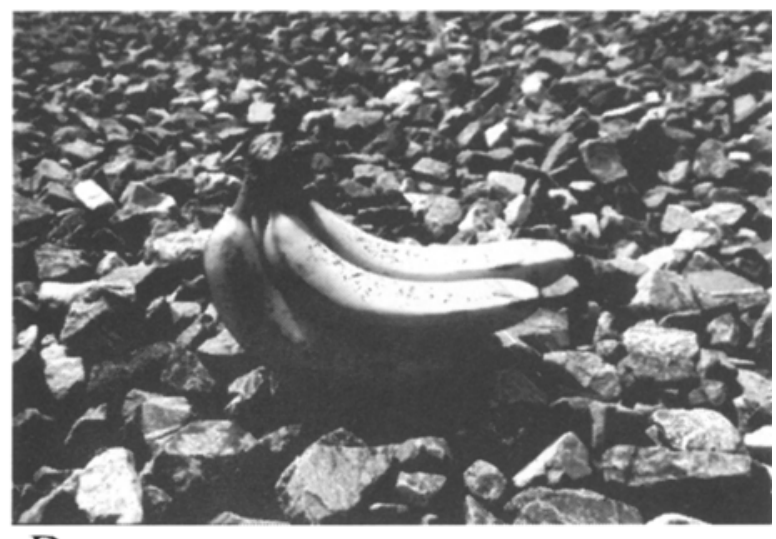

D

Figure 3. Four photographs to be used in the longer demonstration. Note that the bear and the pail are cropped, whereas the tire and the bananas are not.

using rectangles that are 4 in. by 6 in. It is helpful to include the name of the picture to be drawn above each rectangle. Response sheets meeting this description are available on the Web.

Pictures should be presented for $15 \mathrm{sec}$ each in random order, after an instruction such as the following is read.

You will be presented with two (four) photographs of scenes for 15 seconds each. Please pay close attention to each picture and try to remember the main objects and the background in as much detail as possible. Try to remember everything in the picture, including its layout--that is, the size and location of everything in the picture space. In other words, try to retain an exact copy of each picture in memory.

Response sheets should be handed out after the stimulus presentation is complete, and an instruction similar to the one below should be read.

In each rectangle, draw the picture named above in as much detail as possible. Don't worry if you are not a great artist; just do your best to represent everything you saw in the picture. Consider the edges of the rectangle to be the edges of the picture you saw. Try to capture the layout of the picture; that is, try to draw everything in the same relative size and position as in the picture. After you draw each picture, make all the changes you think are necessary, and if you want to clarify any part of your drawing please feel free to use words as labels.

Participants usually take 2-3 min to draw each picture, so the drawing task should take about $5 \mathrm{~min}$ for the shorter demonstration and $10 \mathrm{~min}$ for the longer one.

\section{Results}

When the drawing task is completed, the photographs should be presented again so that participants can make a comparison. It is interesting to note that, although the effect is typically quite large (as in the case of the fork in Figure 2, panel B), when participants first look at their drawings, they sometimes do not notice their error. This failure to notice the error is interesting in itself, suggesting that in viewing scenes, we tend to ignore the "accidentally" imposed boundaries created by the picture's edges. Once participants are directed to examine the boundaries and the sizes of the objects with respect to the picture space, their reactions are usually similar to those 

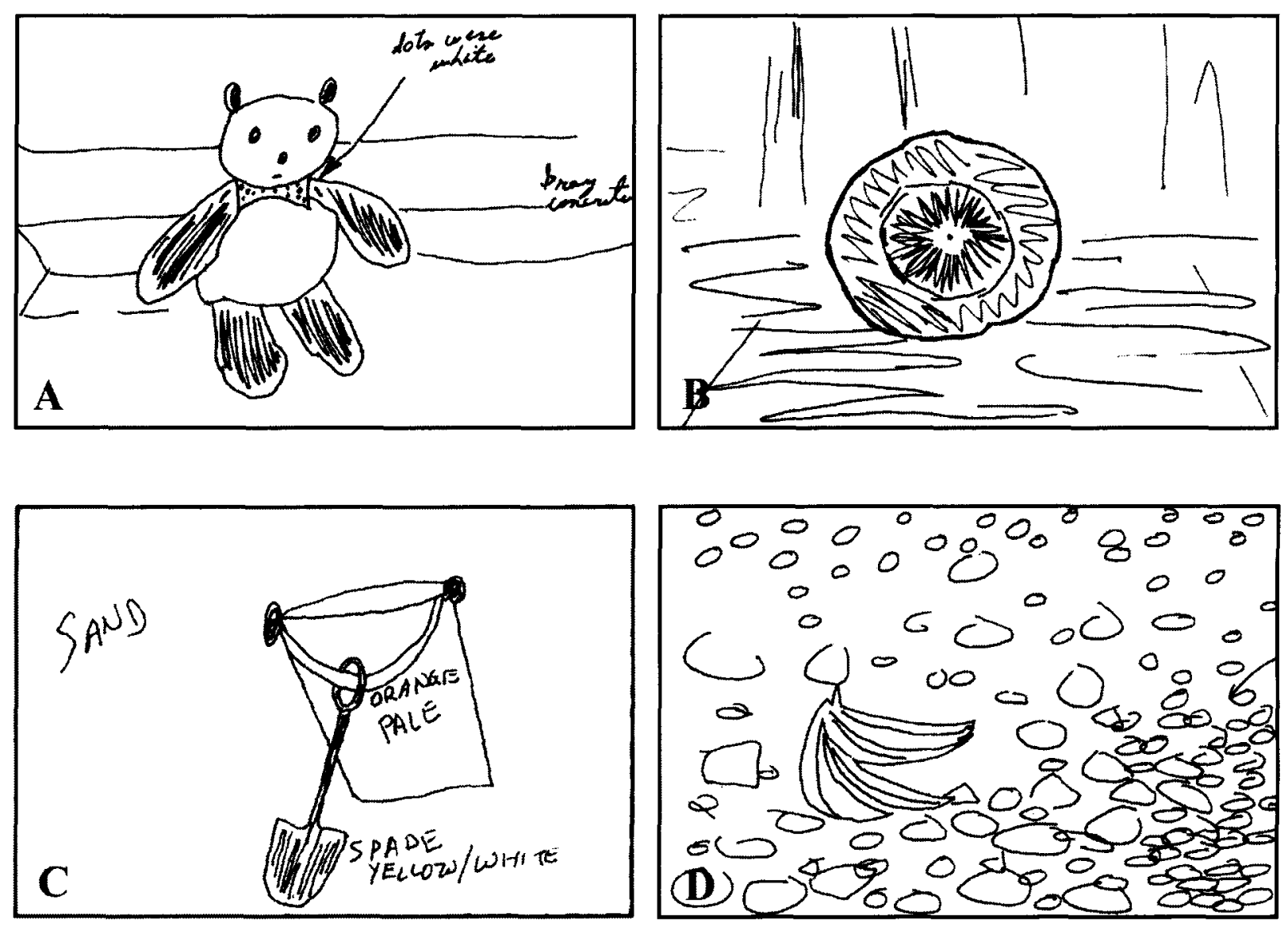

Figure 4. Sample drawings of the photographs in Figure 3 (from participants in Intraub and Berkowits, 1996, Experiment 1). The bear, tire, pail, and bananas were drawn to be $.35, .47, .41$, and .30 of their original size, respectively. The mean area drawn across subjects for each picture in that experiment was $.34, .44, .41$, and .30 , respectively.

obtained during presentations of visual illusions. Participants are typically surprised to see that they have extrapolated so much when recollecting the scenes.

Although boundary extension is obvious on the basis of inspection alone, a quantitative analysis can be readily accomplished. To do this, it is necessary to measure the area of the main object in the stimulus (when it is presented in a 4-in. by 6-in. format) and in the participants' drawings. This can be done by digitizing the drawing and using a computer program that calculates numbers of pixels in an object, or it can be done quite well using a paper-and-pencil method. In the latter case, each participant would trace the outline of the main object from each of his/her drawings onto graph paper. (Note that 10 squares/inch is a common size and has been used in published research on boundary extension.) They would count the number of grid squares that each drawn object covers and divide this number by the number of grid squares that the object covers in the original stimulus.

This calculation results in the proportion of the original object that was drawn by the participant. The mean proportion drawn for each picture should be calculated and .95 confidence intervals constructed around the means to show whether or not they are significantly different from 1. A proportion of 1 is obtained when the object's size is correctly captured in the drawing. A proportion less than 1 occurs when the object covers a smaller area in the picture space, thus indicating boundary extension. A proportion that is greater than 1 occurs when the object covers a larger area in the picture space, thus indicating boundary restriction. Because of photocopier distortions, we are unable to provide reliable area estimations for pictures copied from the journal. However, for stimuli downloaded from the Web, the main objects were measured as follows: bear $=1,136$ square .1 inch, tire $=735$, pail $=900$, bananas $=307$.

Boundary extension should be obtained in memory for all the demonstration photographs. Sample drawings of the photographs in Figure 3 and the proportion drawn for each are shown in Figure 4.

\section{DISCUSSION}

Both demonstrations provide examples of the effects of top-down knowledge on memory for scenes. The demonstration based on Figure 3 and the experiment pro- 
vided on the World-Wide Web can be used to contrast the perceptual schema hypothesis with other possible explanations of boundary extension that are derived from theories with long traditions in psychology.

\section{Object Completion}

A frequently suggested alternative explanation is based on the Gestalt principle of object completion (see, e.g., Ellis, 1955). In many of the close-up pictures used in the first experiments on boundary extension (Intraub \& Richardson, 1989), the main objects in the pictures were cropped by the picture's boundaries (as in Figure 1). The hypothesis is that object completion in memory would force the viewer to extend the boundaries to fit the entire object within the picture space. However, when stimuli with no cropped objects were presented, boundary extension did occur. This observation ruled out the object completion hypothesis (see Intraub et al., 1992, and Intraub \& Bodamer, 1993). Memory for the two pictures in which the objects are not cropped (Figure 3, panels B and D) provide a demonstration of this outcome (see sample drawings in Figure 4, panels B and D). The same point can be made using the recognition procedure described on the Web.

\section{Remembering Prototypic Views}

Another alternative to the perceptual schema explanation of boundary extension is that memory for scenes tends to distort toward a prototypic view. Clearly, there are many instances in which memory for a stimulus shows the influence of prototypic expectations (e.g., Bartlett, 1932; Franks \& Bransford, 1971). Close-ups, by definition, tend to show a view that is closer than the expected, prototypic view. Therefore, when a close-up is remembered, the viewer would be likely to remember a slightly more wide-angle view, and this would yield boundary extension. However, this hypothesis suggests that pictures containing prototypic views should yield no directional distortion, and wide-angle views should be remembered with restricted boundary because they become like the prototype in memory.

As described earlier, research has shown that these predictions are not borne out and that in immediate tests of memory, close-ups show the greatest degree of extension, followed next by prototypic views, and finally by wideangle views, which show little extension or no directional distortion (Intraub et al., 1992; Intraub \& Berkowits, 1996). The demonstration based on Figure 3 will allow students to see that the prototypic views do indeed yield boundary extension. A complete test of this hypothesis that allows participants to compare memory for closeup, prototypic, and wide-angle views of the same scenes can be conducted by running the experiment available on the Web.

\section{Related Research}

Other research on scene processing supports the idea that scene memory does not involve a detailed metric rep- resentation of the visual world, but a representation that is more abstract and schematic. Recent research on memory for visual information from successive eye fixations (i.e., transsaccadic memory), and research on the viewer's surprising inability to detect changes made to a scene under a variety of circumstances support this general view (Grimes, 1996; Irwin, 1993; McConkie \& Currie, 1996; O'Regan, 1992; Rayner \& Pollatsek, 1992; Rensink, O'Regan, \& Clark, 1997; Simons 1996; Simons \& Levin, 1997).

Both implicit and explicit memory tasks have also shown the effects of a scene schema on memory. For example, in an implicit memory experiment, Sanocki and Epstein (1997) demonstrated that priming with a sketch of a scene's layout facilitates subsequent interobject distance judgments in a photograph of the scene. In an explicit memory study, Hock and Schmelzkopf (1980) showed that viewers spontaneously constructed a schematic representation of a street scene after studying a series of views taken from different vantage points.

Experiments from other areas within visual perception and scene processing have provided additional converging evidence for the role of schematic expectations in visual perception and memory (see Intraub, 1997, for a review).

\section{Conclusions}

A demonstration of boundary extension provides a graphic illustration of the role of top-down, schematic knowledge in memory. The concept of a schema is relevant to many areas of cognition, including text comprehension (see, e.g., Bransford \& Johnson, 1972; Kintsch \& van Dijk, 1978; Zwaan \& Radvansky, 1998), social cognition (Fiske \& Taylor, 1991), and, as stressed in the present paper, scene perception and memory. The demonstration provides a useful teaching aid that can be used within any of these contexts at both introductory and advanced levels.

\section{REFERENCES}

AYERS, M. S., \& REDER, L. M. (1998). A theoretical review of the misinformation effect: Predictions from an activation-based memory model. Psychonomic Bulletin \& Review, 5, 1-21.

BARTLETT, F. (1932). Remembering: A study of experimental and social psychology. Cambridge: Cambridge University Press.

Bransford, J. D., \& Johnson, M. K. (1972). Contextual prerequisites for understanding: Some investigations of comprehension and recall. Journal of Verbal Learning \& Verbal Behavior, 11, 717-726.

Ellis, W. D. (Ed. and Trans.) (1955). A source book of Gestalt psychology. London: Routledge \& Kegan Paul.

Fiske, S. T., \& TAYlor, S. E. (1991). Social cognition (2nd ed.). New York: McGraw-Hill.

Franks, J. J., \& BRANSFORD, J. D. (1971). Abstraction of visual patterns. Journal of Experimental Psychology, 90, 65-74.

Grimes, J. (1996). On the failure to detect changes in scenes across saccades. In K. Akins (Ed.), Perception (Vancouver Studies in Cognitive Science, Vol. 5, pp. 89-110). New York: Oxford University Press.

Hochвerg, J. (1978). Perception (2nd ed.) Englewood Cliffs, NJ: Prentice-Hall.

HochBERG, J. (1982). How big is a stimulus? In J. Beck (Ed.), Organization and representation in perception (pp. 191-217). Hillsdale, NJ Erlbaum. 
Hock, H. S., \& Schmelzkopf, K. F. (1980). The abstraction of schematic representations from photographs of real-world scenes. Memory \& Cognition, 8, 543-554.

INTRAUB, H. (1997). The representation of visual scenes. Trends in Cognitive Science, 1, 217-222.

InTRAUB, H., Bender, R. S., \& MANGELS, J. A. (1992). Looking at pictures but remembering scenes. Journal of Experimental Psychology: Learning, Memory, \& Cognition, 18, 180-191.

InTRAUB, H., \& Berkowits, D. (1996). Beyond the edges of a picture. American Journal of Psychology, 109, 581-598.

InTRAUB, H.,\& Bodamer, J. L. (1993). Boundary extension: Fundamental aspect of pictorial representation or encoding artifact? Journal of Experimental Psychology: Learning, Memory, \& Cognition, 19, $1387-1397$.

Intraub, H., Gottesman, C. V., \& Bills, A. (1998). Effects of perceiving and imagining scenes on memory for pictures. Journal of Experimental Psychology: Learning, Memory, \& Cognition, 24, 186-201.

Intraub, H., GotTesman, C. V., Willey E. V., \& Zuk, I. J. (1996). Boundary extension for briefly glimpsed photographs: Do common perceptual processes result in unexpected memory distortions? Journal of Memory \& Language, 35, 118-134.

INTRAUB, H., \& Richardson, M. (1989). Wide-angle memories of close-up scenes. Journal of Experimental Psychology: Learning, Memory, \& Cognition, 15, 179-187.

IRwIN, D. E. (1993). Perceiving an integrated visual world. In D. E. Meyer \& S. Kornblum (Eds.), Attention and performance XIV: Synergies in experimental psychology, artificial intelligence, and cognitive neuroscience (pp. 121-142). Cambridge, MA: MIT Press.

KINTSCH, W., van DiJK, T. A. (1978). Toward a model of text comprehension and production. Psychological Review, 85, 363-394.
Legault, E., \& Standing, L. (1992). Memory for size of drawings and of photographs. Perceptual \& Motor Skills, 75, 121.

LofTus, E. F., \& PALMER, J. C. (1974). Reconstruction of automobile destruction: An example of the interaction between language and memory. Journal of Verbal Learning \& Verbal Behavior, 13, 585-589.

McConkIE, G. W., \& CurrIE, C. B. (1996). Visual stability across saccades while viewing complex pictures. Journal of Experimental Psychology: Human Perception \& Performance, 22, 563-581.

Nyström, M. (1993). Is picture memory wide-angle? Psychological Research Bulletin, 33, 1-16.

O'REGAN, J. K. (1992). Solving the "real" mysteries of visual perception: The world as an outside memory. Canadian Journal of Psychology, 46, 461-488.

Rayner, K., \& Pollatsek, A. (1992). Eye movements and scene perception. Canadian Journal of Psychology, 46, 342-376.

Rensink, R. A., O'REgan, J. K., \& Clark, J. J. (1997). To see or not to see: The need for attention to perceive changes in scenes. Psychological Science, 8, 368-373.

SANOCKI, T., \& EpSteIN, W. (1997). Priming spatial layout of scenes. Psychological Science, 8, 374-378.

Simons, D. J. (1996). In sight, out of mind: When object representations fail. Psychological Science, 7, 301-305.

Simons, D. J., \& Levin, D. T. (1997). Change blindness. Trends in Cognitive Science, 1, 261-267.

ZwaAN, R. A., \& Radvansky, G. A. (1998). Situation models in language comprehension and memory. Psychological Bulletin, 123, 162-185.

(Manuscript received November 4, 1997; revision accepted for publication August 5, 1998.) 